\title{
Genetic and Morphological Comparisons of Lesser Celandine (Ficaria Verna) Invasions Suggest Regionally Widespread Clonal and Sexual Reproduction
}

\author{
Kali Zoe Mattingly ( $\sim$ kzmattingly@gmail.com ) \\ The Ohio State University https://orcid.org/0000-0001-7987-6061 \\ Charles T. C. Day \\ Cornell University \\ Emily S. J. Rauschert \\ Cleveland State University \\ Aaron Tayal \\ The Ohio State University \\ Stephen M. Hovick \\ The Ohio State University
}

\section{Research Article}

Keywords: invasive plants, landscape genetics, floral morphology, isolation by resistance, dispersal

Posted Date: January 24th, 2022

DOI: https://doi.org/10.21203/rs.3.rs-1168034/v1

License: (c) (1) This work is licensed under a Creative Commons Attribution 4.0 International License. Read Full License 


\section{Abstract}

Both asexual and sexual reproduction can provide important keys to the success of invasive species. A species with the potential for both strategies is lesser celandine (Ficaria verna), a European native with multiple subspecies that have been introduced in North America as ornamentals and escaped cultivation. Although the genetic and morphological diversity of celandine has been studied in Europe, few studies have examined North American populations. We aimed to document genotypic and phenotypic diversity at a regional scale. We compared sequence-related amplified polymorphism (SRAP) genotypes of 64 individuals collected from Columbus, Cleveland, and Cincinnati, $\mathrm{OH}$. We phenotyped 129 individuals from across the same regions and from Louisville, KY, measuring trait values in an outdoor common garden experiment. The SRAP markers were highly polymorphic and revealed surprising genetic diversity. Genetic and trait variation was structured across regions, but we also saw high variation within regions. Cleveland populations differed the most genetically and morphologically, with notably smaller flowers. Of individuals that flowered, many produced expanded achenes, and all regions had individuals that made asexual bulbils. Trait data suggested subspecies verna or ficariiformis may be present in these regions. Their genetically admixed nature, along with achene production and a potential relationship between genetic diversity and the ability to produce achenes all support sexual reproduction. Sexual and asexual propagules may spread by different vectors, and our resistance analyses indicated water dispersal and habitat availability may contribute to genetic structure. These findings suggest celandine may have substantial potential for further spread and for evolutionary change.

\section{Introduction}

Urban areas are hotspots of biological invasions for multiple taxa (McKinney 2006; Štajerová et al. 2017; Borden and Flory 2021). In part, this reflects intense propagule pressure in cities resulting from anthropocentric industries such as horticulture and the pet trade, which introduce many species in large numbers. The success of urban invaders may also be a function of enhanced genetic or morphological diversity in introduced populations that have originated from a diversity of sources (Dlugosch and Parker 2008). Such variation in diversity matters in the short term as poorly adapted genotypes are filtered out and well-adapted genotypes increase in abundance (e.g., Lavergne and Molofsky 2007). In the longer term, admixture in higher diversity populations can lead to enhanced evolutionary potential. Characterizing the genetic and morphological diversity of urban invader populations is thus critically important, both for understanding the key pathways by which a species has been introduced and for making inferences about its longer-term invasion potential (Borden and Flory 2021).

Among the many putative invasiveness traits that have been identified, variation in reproductive mode has perhaps the greatest potential to influence both immediate and longer-term success of introduced species (Pyšek and Richardson 2008). The ability to reproduce asexually is well-known to enhance colonization success (Baker 1955), especially in plants, where clonal reproduction allows for the proliferation of well-adapted genotypes even in the absence of pollination vectors or compatible mates (Barrett 2015). In contrast, sexual reproduction yields greater variability in successive generations than does asexual reproduction, potentially enhancing the speed at which populations can adapt to novel conditions-such as the unique stressors of novel urban environments. Not surprisingly then, many successful invasive species reproduce both sexually and asexually, leading to highly diverse populations that can also propagate clonally (Pyšek and Richardson 2008). However, for species that vary among populations in the capacity to reproduce both sexually and asexually, local establishment and spread may be highly variable. This is the case for North American populations of Phragmites australis, which are capable of producing seeds via sexual reproduction only where population diversity is sufficiently high (Kettenring et al. 2011).

Jointly examining patterns of genetic and morphological intraspecific variability may help clarify how an invasion has spread across the introduced landscape. When the genotypes and phenotypes in introduced populations correspond closely to those of native sources, indicating little recombination, asexual spread has likely predominated. In contrast, a lack of correspondence would suggest sexual reproduction has yielded admixed genotypes. This distinction may be particularly clear in systems where these different reproductive modes are associated with different types of dispersules, such as sexually-produced seeds that disperse by birds versus vegetatively-produced rhizome fragments that lack a capacity for such long-distance dispersal. 
One invasive species characterized by diverse reproductive biology is lesser celandine (Ficaria verna; previously known as Ranunculus ficaria), a spring ephemeral wildflower native to Europe and Northern Africa that has been introduced to North America, New Zealand, and Japan as a horticultural plant (Axtell et al. 2010). It is considered invasive in North America, where it colonizes forested riparian and floodplain habitats in much of the eastern United States and Canada, as well as the Pacific Northwest (Axtell et al. 2010). Locally, celandine produces dense monocultures that may negatively impact native plants (Axtell et al. 2010). In its native range, celandine is separated into either five (Sell 1994) or seven subspecies (Veldkamp 2015). The nomenclature for lesser celandine and its subspecies has been disputed; we follow Veldkamp (2015), which reflects recent molecular evidence in support of Ficaria as a genus distinct from Ranunculus (Emadzadze et al. 2010). The celandine subspecies differ in reproductive biology (Sell 1994; Veldkamp 2015). All subspecies can spread clonally via belowground tubers (Axtell et al. 2010), but two subspecies also reproduce clonally via small bulbils held aboveground in the leaf axils: ficariiformis and verna (Veldkamp 2015; syn. bulbi(li)fera, Ranunculus ficaria var. or subsp. bulbi(li)fer or bulbulifer, Sell 1994).

The relative importance of spread by tubers, bulbils, and seeds is unknown. In its native range, spread of celandine does not appear to be strongly dispersal- or recruitment-limited (Verheyen and Hermy 2001). Compared to tubers, bulbils might be more likely to spread long distances along waterways during flooding events or be tracked to new areas by animals or people (Sell 1994; Axtell et al. 2010). The bulbiferous subspecies also frequently occur in higher local abundances than non-bulbiferous ones (Taylor and Markham 1978), highlighting the potential importance of these structures for spread. It was originally reported that bulbiferous subspecies in Europe rarely produce viable seeds and thus rely solely on clonal reproduction (Metcalfe 1939). Some populations are reportedly purely clonal (Verheyen and Hermy 2001), but recent European work has shown that some bulbiferous celandine can produce viable seeds (Jung et al. 2008; Popelka et al. 2019). Celandine population dynamics appear to be further influenced by disturbance, with spread exacerbated by mowing (Reisch and Scheitler 2008) and reproductive output affected by flooding intensity (Jung et al. 2008). Soil features are also associated with variation in plant performance, with lower bulbil and tuber production occurring in sites with sandier soils (Kermack and Rauschert 2019) and higher bulbil production in sites with fungal communities containing dark septate endophytes and ericoid mycorrhizae (Paolucci et al. 2021).

In North America, at least five celandine subspecies have been observed (Post et al. 2009), and these five subspecies also differ in ploidy. Both subspecies that produce axillary bulbils (verna and ficariiformis), along with one that does not, chrysocephala (syn. Ranunculus ficaria subsp. chrysocephalus, Sell 1994), are tetraploid. The remaining two subspecies described by Veldkamp (2015) - calthifolia (syn. calthifolius, Sell 1994) and fertilis (syn. ficaria, Sell 1994)-are diploid. Triploids are also occasionally observed, usually in mixed populations with diploids and tetraploids (Gill 1972; Marchant and Brighton 1973), suggesting some crossing among diploids and tetraploids. Apart from reproductive biology, the subspecies observed in North America can be partially separated based on flower and leaf size. Field-collected plants in Europe from subspecies ficariiformis and chrysocephala have, on average, larger leaf petioles, leaf blades, flowers, and achenes than subspecies verna, fertilis, and calthifolius (Sell 1994; Veldkamp 2015). Post and colleagues (2009) measured North American herbarium specimens and found similar morphological differences among subspecies with respect to leaf and floral measurements. However, these differences are subtle, and variation among individuals means that subspecies often cannot be distinguished from each other in the field (Veldkamp 2015; Post et al. 2009; Whittemore 2020), and only some apparently distinguishing features persist when individuals are grown under controlled conditions (Jones 1966, as cited by Taylor and Markham 1978).

Introduced celandine populations have been expanding over the past few decades, and the species is now listed as invasive in both the Eastern US and the Pacific Northwest (USDA NRCS 2021). Documenting variability within and among populations will help better understand the biology of this cryptic set of subspecies, their potential for evolutionary change, and their modes of spread. If sexual reproduction is common, this increases the likelihood that celandine may adapt to changing environmental conditions. Such a finding would have management implications, especially if certain regions were found to have populations that had particularly high evolutionary potential. 
To pursue such insights, we explored patterns of genetic and morphological variability in invasive celandine populations in urban areas. We compared four regions: Louisville, KY, and Cincinnati, Columbus, and Cleveland, $\mathrm{OH}$. All subspecies except chrysocephala are reportedly present with overlapping distributions in this area (Post et al. 2009). Clonal propagules (tubers and bulbils) are assumed to be the primary modes of spread in introduced populations, but the regions also appear to differ in seed production capacity. Seeds have been documented in Louisville (Masters and Emery 2015), anecdotally observed in Columbus, and seem largely absent in Cleveland (pers. obs.). We addressed several aims related to our primary research question: To what extent are celandine populations differentiated, both genetically and morphologically (suggesting subspecies fidelity and negligible gene flow), versus being highly similar across the landscape (suggesting sexual reproduction and/or substantial gene flow)? First, we described genetic variation, using an accessible fragment analysis technique. We predicted that genetic structure would mostly correspond to separate regions, which have each had different introduction histories. Next, we described celandine's morphological variation and tested for correlations between morphology and genetic variation. We predicted that morphological variation would also be structured regionally, corresponding to genetic variation, and that if samples could be assigned to described subspecies, we suspected the two bulbiferous subspecies would predominate. Finally, we quantified the relative importance of key landscape-scale factors that may influence genetic distance between celandine populations. These factors included putatively important conduits of or resistors to celandine establishment or spread, such as geographic proximity, spatial variables associated with likely introduction and dispersal pathways, and known environmental conditions in which celandine occurs.

\section{Methods}

\section{Overview}

Genetic and morphological data were collected via independent sampling schemes, from different individuals at different times and from partially overlapping sites. To compare these two datasets, we hierarchically grouped samples into regions and, within regions, populations (Fig. 1, Table S1). Regions corresponded to the metropolitan areas represented-Louisville, KY (LOU, morphological data only); Cincinnati, $\mathrm{OH}(\mathrm{CIN})$; Cleveland, $\mathrm{OH}$ (CLE)-and, within the more exhaustively sampled Columbus area, East and Central Columbus. The two Columbus regions corresponded to different watersheds in East and Central Columbus (Fig. 1b,c), and we further geographically subdivided Columbus samples into populations nested within regions (Fig. 1b,C; Table S1): East Columbus included BSP, BTC, and BWC, while Central Columbus included CAT, CCC, and SCI. Region and population assignment weighted mean GPS locations coincided fairly well for both the genetic and morphological datasets (Table S1), with the omission of some morphological samples collected far upstream on the Olentangy and Scioto Rivers (Fig. 1c). All population SCl samples (Central Columbus; Fig. 1b,c) were collected from the Scioto River south of its confluence with the Olentangy River (Central Columbus), but both genetic samples were also south of the confluence with the East Columbus watershed (Fig. 1b).

\section{Population genetics}

\section{Sample collection}

To prepare to assess genetic structure of celandine, we first surveyed the Columbus metropolitan area for celandine presence in February-April 2019. During this time, celandine plants were beginning to leaf out while most canopy trees were still leafless. We used Google Maps satellite imagery to locate potential sites that were public access, forested riparian areas and sampled a subset of these to record celandine presence/absence (Fig. 1a). To aim to collect genetically unique samples, at each celandine-present site we haphazardly threw a $0.5 \mathrm{~m}^{2}$ quadrat in replicate patches separated by $\geq 3 \mathrm{~m}$, harvesting aboveground tissue from a single plant per quadrat for DNA extraction. We consulted local experts for information about celandine populations in the Cleveland and Cincinnati areas and obtained additional tissue samples from these locations.

\section{Genotyping}

We used a modified CTAB protocol (Doyle and Doyle 1987; Wolfe 2005) to extract DNA. Protocol modifications included: adjusting solution volumes for extraction in $1.2 \mathrm{~mL}$ tubes, homogenizing tissue with a Mixer Mill MM 400 (Retsch), increasing 
concentration (per $\mathrm{mL}$ of CTAB buffer) to $20 \mu \mathrm{L} / \mathrm{mL}$ for 2-mercaptoethanol and $0.02 \mathrm{~g} / \mathrm{mL}$ for polyvinylpyrrolidone, precipitating with $100 \% \mathrm{EtOH}$ rather than $75 \%$, omitting final cleaning with ammonium acetate solution (as we obtained good results without doing so), and resuspending the final extracted DNA in 100 $\mu \mathrm{L}$ Milli-Q purified water (Millipore Sigma) with $1 \mu \mathrm{L}$ RNAse A. We extracted DNA from $50-90 \mathrm{mg}$ tissue from leaves and floral meristems; both tissue types produced high DNA quantity and quality, with floral meristems yielding slightly higher concentrations. We screened DNA by running $1 \%$ agarose test gels and by estimating DNA concentration and impurities with NanoDrop (ThermoFisher Scientific). We produced genotypes with sequence-related amplified polymorphism (SRAP, Li and Quiros 2001), which is a low cost, reproducible genetic marker method for comparisons at the subspecies and population level (Robarts and Wolfe 2014). Similar to amplified fragment length polymorphism (AFLP), SRAP markers are scored as present or absent and based on PCR amplification of variably sized DNA fragments. Each PCR included: $1 \mu \mathrm{L}$ undiluted DNA template, $5 \mu \mathrm{L}$ DreamTaq Hot Start Green PCR Master Mix (ThermoFisher Scientific), $4.5 \mu \mathrm{L}$ Milli-Q purified water, $0.25 \mu \mathrm{L}(2 \mu \mathrm{M})$ fluorescently tagged forward primer, and $0.25 \mu \mathrm{L}(2 \mu \mathrm{M})$ reverse primer (Sigma Aldrich). We ran PCR on a SimpliAmp Thermal Cycler (Applied Biosystems) using the program described by Li and Quiros (2001).

We first screened primer pairs for variability among individuals. We tested at least six individuals for each of 32 combinations of forward and reverse primers (Table S2). Nine pairs produced good band differentiation when screened on $1 \%$ agarose gels (Table S2). We ran PCRs using these nine pairs and prepared them for capillary electrophoresis fragment analysis by filling 96-

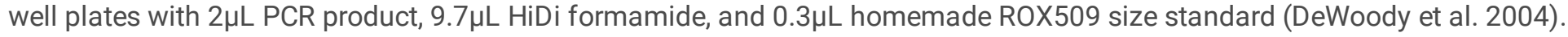
Samples were sent on ice for analysis by the Cornell University Biotechnology Resource Center (Applied Biosystems 3730xl). Preliminary screening of the nine primer pairs showed that four (Table S2) produced highly repeatable genotypes when fluorescently tagged fragments were analysed. We used these four pairs for final analyses. A preliminary screening of electropherograms showed many samples (some full plates) with noisy or unclear data. Therefore, we conservatively scored fragment data as follows. First, we manually examined each electropherogram in Peak Scanner (v. 2.0, Applied Biosystems), discarding samples with noisy or unclear data for the sample, size standard, or both. We considered samples too noisy if fragment peaks and background noise were separated by $\sim<50$ relative fluorescence units. We then imported the data into $R$ ( $v$. 3.6.0, R Core Team 2019) for scoring with RawGeno (v. 2.0-1, Arrigo et al. 2009; Arrigo et al. 2012; Herrmann et al. 2013). We discarded samples having outlier fragment numbers ( $>95$ th $\%$ ile, $<5$ th \%ile). We scored fragments within the range of the size standard (80-508bp) that had a relative fluorescence of at least 50, allowing bin sizes of 1-2bp. We further filtered scored fragments according to reproducibility across replicated genotypes (same individual and primer pair, separate well on fragment analyser) for 4-7 individuals per primer pair. For each scored fragment, we calculated the percent of replicated pairs that matched for the presence of that fragment. We conservatively required at least $80 \%$ repeatability to retain a scored fragment, meaning that when a marker was present in one sample it must also be present in the paired replicate, in at least $80 \%$ of cases (i.e., $\geq 4$ out of 5 replicates). Markers that could not be tested for reproducibility were dropped. Finally, we filtered fragment data for potential "pull-ups," or artifacts where capillary electrophoresis blurs the dyes of the size standard and the sample, resulting in an erroneously scored fragment. We removed any scored fragments $\pm 0.1 \mathrm{bp}$ of size standard. Then, for all scored markers within $\pm 0.5 \mathrm{bp}$ of size standards, we checked their frequency across all samples, with the idea that uncommon fragments might be noise. All such markers had frequencies of $\geq 25 \%$ across individuals, except one that was only present in $3 / 64$ samples, which we discarded.

\section{Morphology}

\section{Sample collection}

Between February and March 2020, we collected plants from a partially overlapping set of sites in Ohio, from which we had previously collected samples from for genetic analyses (compare Fig. 1b vs. 1c and 1d vs. 1e), as well as from sites in Louisville, KY (Fig. 1c,e). We collected morphological specimens from 43 unique collection sites. At each site, we collected three samples that were at least $5 \mathrm{~m}$ apart to reduce the likelihood of sampling identical genotypes, for a total of 129 clumps of celandine plants. We carefully dug underneath the celandine tubers to avoid damaging them and stored samples at $4^{\circ} \mathrm{C}$ until replanting. 
We sought to align the genetic and morphological datasets by assigning samples a priori into populations based on geographic proximity. To facilitate comparisons between datasets, we also focus primarily on trends at the regional scale, which we consider to be the most germane for assessing potential differentiation in an introduced species that has a high propensity to spread. The four regions sampled have had different histories with respect to celandine. The species has been present for at least 70 years in Cleveland (OSU MBD 2021) and Cincinnati (Lawrence 1971). Columbus herbarium records show escaped individuals appearing within the past 30-50 years (OSU MBD 2021). The first escapes in Louisville appear to have occurred within the past 30 years (Jeffrey Masters, University of Louisville, pers. comm.). All areas have seen considerable spread over the past 15 years (pers. obs.; Cory Christopher, Cincinnati Nature Center; Carrie Morrow, Columbus Metro Parks; Major Waltman, Olmsted Parks Conservancy; pers. comm.), with several public lands agencies recently prioritizing its management (Mack 2008; pers. obs.; Danielle Frevola, Cincinnati Nature Center; Major Waltman, Olmsted Parks Conservancy; pers. comm.).

\section{Phenotyping}

In March 2020, we established an outdoor common garden to phenotype plants (Table 1 for all traits measured). We carefully washed the soil away from the roots of each sample and selected three individual plants that lacked major damage. For the plant with the longest tuber, we recorded number of tubers as an indicator of pre-experiment size. We potted all three plants into a single $10 \mathrm{~cm}$ diameter round pot filled with moist potting soil (LM-AP All Purpose Mix; Lambert, Quebec, Canada) and randomized pot positions in an outdoor location in Columbus, Ohio that received sun for $\sim 1 / 3$ of the day and shade for $\sim 2 / 3$ of the day.

Table 1

Morphological traits recorded for celandine plants. Bold denotes traits analysed with linear mixed effects models.

\begin{tabular}{|lll|}
\hline Trait name & Unit & Trait Explanation \\
\hline Number of tubers & & Number of tubers on plant 1 in the pot at the time of planting \\
\hline Petal length & $\mathrm{mm}$ & Length from base of the sepal to tip of the sepal \\
\hline Petal width & $\mathrm{mm}$ & Length from base of the petal to the petal tip \\
\hline Carpel whorl diameter & $\mathrm{mm}$ & Width at the widest point of a flattened petal \\
\hline Leaf blade length & $\mathrm{mm}$ & Diameter of the spherical carpel whorl \\
\hline Leaf blade width & $\mathrm{mm}$ & Distance from the point where petiole meets leaf blade to the blade tip \\
\hline Leaf blade length:width ratio & $\mathrm{mm}$ & Ratio of previous two traits \\
\hline Leaf lobe length & $\mathrm{mm}$ & Distance from the tip of the lobe to the point where petiole meets blade \\
\hline Leaf petiole length & $\mathrm{mm}$ & Distance from petiole base to the point where petiole meets blade \\
\hline Presence of expanded achenes & & Presence of expanded achenes in the weeks following flowering \\
\hline Maximum achene length & $\mathrm{mm}$ & Maximum achene length of the achenes that are expanded \\
\hline Presence of axillary bulbils & & Presence of bulbils in leaf axils during senescence \\
\hline
\end{tabular}

We watered plants as needed and monitored them for flowering, collecting floral trait data from the first flower that opened in each pot (for the 59 plants that flowered; see Table 1 for trait details). To eventually measure seed production, we used a tie to mark the flower from which we collected floral trait data. We collected all floral data in April 2020. In late April 2020, we collected leaf data for the plant with the longest tuber in every pot (Table 1), measuring a suite of traits for that plant's single leaf with the longest blade length. In most cases, floral and leaf traits were taken from the same plant. In May 2020, we recorded data on seed and bulbil production (Table 1), noting whether the achenes expanded into seeds and whether bulbils 
were present in the leaf axils (presence of bulbils was not apparent until this later phenological stage). Soon thereafter, the plants naturally senesced as they entered summer dormancy.

\section{Data analysis}

\section{Population genetics}

For each primer pair, we present the following summary statistics: number of fragments, percent polymorphism, fragments per individual, frequency of each fragment across individuals, percent repeatability of fragments across replicates, percent repeatability of replicates across fragments, and polymorphism information content (Table S3). For dominant markers like SRAPs, polymorphism information content is an index from zero to 0.5 (Serrote et al. 2020), where zero is monomorphic and 0.5 is highly informative. We next used a priori population groupings to compare genetic diversity (Nei's gene diversity, Nei 1978; poppr::poppr, Kamvar et al. 2014, R v. 4.0.3, R Core Team 2020) and pairwise genetic distance among populations (Dice's coefficient, Dice 1945; ade4::dist.binary, Dray and Dufour 2007).

We assessed potential clones using RClone (Bailleul et al. 2006, an R-based implementation of GENCLONE, Arnaud-Haond and Belkhir 2007). We did not use a priori population information for this analysis, to detect celandine clones that might have been spread across populations and regions due to horticultural practices. We first obtained multilocus genotypes for each individual. Shared multilocus genotypes can indicate clones, and we evaluated the likelihood of clonality against probabilities that shared genotypes arose from sexual reproduction and random mating $\left(\mathrm{p}_{\text {gen }}\right)$ or from distinct sexual reproductive events $\left(p_{\text {sex }}\right)$ (Arnaud-Haond et al. 2007). Unique multilocus genotypes can indicate true genets, and in this context $p_{\text {gen }}$ is informative regarding the probability of an individual being assigned to a unique multilocus genotype by chance due to low resolving power of the genetic data (Ortego et al. 2010).

To identify genetically based clusters (K), we used STRUCTURE (v 2.3.4, Pritchard et al. 2000). We ran the algorithm without population assignments, assuming admixture to be possible. We also assumed diploidy, despite the occurrence of diploid, triploid, and tetraploid cytotypes within the species (Sell 1994). Assuming diploidy was conservative given that we lacked ploidy data for our samples. Because SRAPs are dominant markers, erroneously assuming diploidy would lead to error in estimation of absolute genetic distances among clusters but would not affect relative patterns of differences among clusters (Falush et al. 2007; Schenk et al. 2008).

For STRUCTURE, we analysed two separate datasets: 1) all 64 individuals and 2) only the 51 individuals from Columbus, which was more intensively sampled, and which was more likely to meet the assumption of gene flow among individuals. We ran preliminary analyses with a burn-in of 20,000 and 200,000 MCMC iterations, with 3 replicate runs for K values of 1 to 10 . We evaluated K values with STRUCTURE Harvester (Earl and vonHoldt 2012) and the method of Evanno et al. (2005). Analyses indicated the highest likelihoods for $K \leq 4$ with both datasets. Therefore, we ran final analyses with $K$ values of 1 to 4 , a burn-in of 100,000, 500,000 MCMC iterations, and 10 replicates for each K. For the final analyses, we again evaluated K values with STRUCTURE Harvester and the Evanno method. Then, for the most supported K solutions, we used CLUMPP (v. 1.1.2b, Jakobsson and Rosenberg 2007) to obtain consensus among the 10 replicate runs. We present mean clustering assignment probabilities from CLUMPP as our final STRUCTURE results.

As an independent examination of clustering in the genetic data, more assumption-free than STRUCTURE (Jombart et al. 2009), we used principal coordinates analysis (PCoA, ade4::dudi.pco, Dray and Dufour 2007). As for STRUCTURE, we performed PCoAs on both the full dataset from all 64 individuals and from the 51 Columbus individuals only. For these analyses, we deleted the single monomorphic allele and transformed the binary presence/absence matrix into genetic distance (Dice's coefficient). We present PCoAs without a priori population assignment. Plots of the top PCo's qualitatively assess how PCo clusters correspond to our a priori populations and STRUCTURE clusters.

We were also interested in examining how genetic variability was partitioned across the landscape at different geographic scales. We used analysis of molecular variance (AMOVA) to assess the ability of categorical predictors to describe genetic variation (ade4::amova, Dray and Dufour 2007). For both the full and Columbus-only datasets, we removed the single 
monomorphic allele and then used separate AMOVAs to estimate the percent of genetic variability partitioned among 1) our a priori populations; 2) regions (Cincinnati, Cleveland, East Columbus, Central Columbus); and 3) populations nested within regions. We used 9999 permutations to obtain p-values for assessing significance (ade4::randtest, Dray and Dufour 2007).

\section{Morphology}

We used Pearson correlations to ensure our set of morphological traits were not so highly correlated with each other as to be redundant (all $|r|<0.8$ ). Because leaf blade width and blade length were highly correlated ( $r=0.874)$, we retained blade width as an indicator of leaf size and then added the ratio of blade length:width as an indicator of leaf shape. For each trait analysed (Table 1), we used a linear mixed effects model (Ime4::Imer, Bates et al. 2015; R v. 4.0.2, R Core Team 2020) to investigate if trait values varied by region (Cincinnati, Cleveland, East Columbus, Central Columbus). We omitted morphological data from Louisville in these analyses due to low sample size ( $n=6$ for leaf traits, $n=2$ for floral traits) but included them in figures for visual comparison. Where applicable, we also plot on figures the subspecies trait values as described by Sell (1994) and Post et al. (2009), to aid in potential subspecies identification. All models included two covariates to account for any effects of size or phenological stage at collection (number of tubers and collection date, respectively), as well as a random effect to account for plants coming from the same collection site. We did not analyse data on the presence of expanded achenes or presence of axillary bulbils due model convergence issues. We report p-values from Type III F tests (car::Anova, Fox and Weisberg 2019) and pairwise comparisons with Tukey corrections to make inferences about trait differences among regions (Ismeans, Length 2016).

\section{Predictors of genetic variation}

We tested relationships between genetic and phenotypic variation with Mantel tests. We compared the matrix of pairwise genetic distances (Dice's coefficients) to matrices of the absolute value of pairwise differences (stats::dist) between population level $(n=8)$ trait means, testing whether genetic divergence among populations corresponded to trait divergence. We also analysed trait variances, to test whether genetic variation corresponded to trait variation. These tests were the only analyses including both the genetic and morphological datasets, and the only analyses for which morphological samples were assigned to a priori populations (other morphological analyses compared only regions). To achieve reasonable population consensus, we omitted some morphological samples that were not geographically close to any a priori population (Fig. 1c).

To test hypotheses about spatially explicit factors affecting genetic structure, we assessed relationships between the genetic distance matrix and eight continuous spatially explicit predictors. These analyses were only conducted using the dataset of individuals within the Columbus region $(n=51)$ because it fulfilled model assumptions of a landscape sampled relatively evenly and where gene flow among individuals is relatively likely. We used maximum likelihood population effects mixed modelling (Clarke et al. 2002; ResistanceGA::mlpe_rga, Peterman 2018), where the random effect accounts for shared membership across pairwise comparisons of individuals. We defined a full model including all eight spatially explicit predictors, which were centered and scaled (base::scale) to allow for comparison of model coefficients. We used backwards selection to identify which predictors to retain, requiring that the final model include only significant predictors assessed according to $p$-values from Type III Wald $X^{2}$ tests (car::Anova, Fox and Weisberg 2019). At each model simplification step, we checked model assumptions by examining residual plots and calculating variance inflation factors (VIF) to test for multicollinearity among predictors. For one predictor with high VIF (canopy), we checked its effects on final results by performing backwards selection both with and without its inclusion. Both analyses yielded the same final model, which did not include canopy. Therefore, we report statistics from the test of the full model. For the percent variation explained by the final model, we calculated marginal $\mathrm{R}^{2}$ (MuMIN::r.squaredGLMM, Barton 2020).

For three of our spatially explicit predictors, we derived pairwise distance matrices comparing each individual. The Euclidean distance matrix was calculated between pairs of collection site GPS points (NAD27, UTM zone 17N, meters), to test the hypothesis of isolation by distance. We also included two spatially explicit predictors to test the hypothesis that waterborne dispersal contributes to population establishment. We used waterway polylines (USGS 2021) to calculate distance between an individual and the closest waterway (geosphere::dist2Line, Hijmans 2019) and total flow distance, or the shortest total directional distance along a waterway between individuals (riverdist::upstream, Tyers 2020). The sign of flow distance is 
interpreted such that a negative value means the second point in a pair is downstream of the first point, and values closer to zero represent high connectivity.

We also tested hypotheses of isolation by resistance, or genetic isolation resulting from landscape features other than geographic distance alone (McRae 2006). Examining the relationship of landscape features to estimated resistance can provide insights into how features might act as resistors or conductors of gene flow. We estimated resistance surfaces for our remaining five spatially explicit predictors from 30x30m resolution rasters created with tools from ArcGIS Pro (ESRI 2018). Rasters were all cropped to the same rectangular map extent (Fig. S1), which included a buffer of $2 \mathrm{~km}$ around sampled individuals to avoid edge effects. We created a slope raster (Fig. S1a) from DEMs (OGRIP 2021). We based a raster of development intensity (Fig. S1b) on the percent impervious surfaces from the 2016 National Land Cover Database (Dewitz 2019). To approximate the potential for propagule inputs due to residential landscaping, we created an income raster (Fig. S1c) based on median household income data (USCB 2019a) at the level of census tract (USCB 2019b). Two non-residential tracts had no such data, so we replaced these missing values with the mean income for the entire mapped extent. We also created rasters of canopy cover (USDA FS 2019; Fig. S1d) and soil percent sand content (Fig. S1e). Data for area- and depth-weighted average sand content were available for most soil map units (USGS 2014). We filled in missing data by calculating averages based on SoilWeb map unit reports (O'Geen et al. 2017) and filling in non-soil map units (gravel pits and water) with the mean value for the entire mapped extent.

We used ResistanceGA (Peterman 2018) implementing CIRCUITSCAPE (McRae et al. 2008) to estimate the five pairwise resistance matrices to be analysed in our mixed model. This method optimizes CIRCUITSCAPE resistance distances by comparing iteratively estimated resistance values to pairwise genetic distances, optimizing the relationship according to Akaike Information Criterion. We excluded pairwise comparisons between samples with coordinates falling within the same 30x30m raster cell (71/1275 comparisons) and omitted these comparisons from the subsequent mixed models. We allowed iterations to explore all potential shapes of the relationship between genetic and resistance distance, running for up to 1000 iterations. We ran at least two independent runs for each of the five rasters to ensure consistency of estimates. Interpretation of the estimated resistance matrices is such that higher resistance values suggest barriers to gene flow and lower values indicate greater gene flow (dispersal).

\section{Results}

\section{Genetics descriptive statistics}

The four SRAP loci yielded a total of 166 markers across the 64 individuals (Table S3). Only 1/166 was monomorphic. Polymorphism information content was high for all loci, ranging from 0.408 to 0.478 (Table S3), suggesting these markers were highly informative. Repeatability statistics showed high accuracy for scored markers, both for marker presence across replicates (means $94-100 \%$, Table S3) and across all fragments within a replicate (means $96-100 \%$, Table S3). No individuals shared mulitlocus genotypes, with $\mathrm{p}_{\text {gen }}<0.01$ for all individuals, suggesting the data included no clones.

Nei's gene diversity for populations (Table 2) was lowest for Cincinnati (0.251) and Cleveland (0.270) and highest for Columbus (mean of 0.324). Within Columbus, the farthest downstream populations (BTC and SCl, Fig. 1b) had the highest diversity (Table 2), potentially consistent with greater admixture due to water dispersal. Dice's genetic distance calculated among a priori populations ranged 0.234 to 0.468 (Table 2). The most similar were the two Central Columbus populations CAT and CCC (0.234). Cleveland differentiated most from other populations, with all pairwise distances $>0.4$. The most dissimilar were Cleveland and Cincinnati (0.468), which are also the most geographically separated. Cincinnati was more similar to East Columbus (BSP, BTC, BWC, mean 0.338 \pm 0.016 SE) than to Central Columbus populations (CCC, CAT, SCl, mean $0.424 \pm 0.013$ SE) (Table 2). 
Table 2

Comparisons of Nei's (1978) gene diversity and genetic distance (Dice 1945) among a priori populations.

\begin{tabular}{|c|c|c|c|c|c|c|c|c|c|c|}
\hline \multirow[b]{2}{*}{ Population } & \multirow[b]{2}{*}{$\begin{array}{l}\text { Sample } \\
\text { size }\end{array}$} & \multirow{2}{*}{$\begin{array}{l}\text { Nei's gene } \\
\text { diversity }\end{array}$} & \multicolumn{8}{|c|}{ Dice's genetic distance } \\
\hline & & & BSP & BTC & BWC & CAT & $\mathrm{CCC}$ & $\mathrm{SCl}$ & CIN & CLE \\
\hline BSP (Schneider Park) & 5 & 0.274 & - & & & & & & & \\
\hline $\begin{array}{l}\text { BTC (Blacklick and } \\
\text { Three Creeks) }\end{array}$ & 9 & 0.325 & 0.332 & - & & & & & & \\
\hline BWC (Big Walnut Creek) & 8 & 0.259 & 0.320 & 0.289 & - & & & & & \\
\hline $\begin{array}{l}\text { CAT (Clintonville and } \\
\text { Arlington tributaries) }\end{array}$ & 9 & 0.318 & 0.368 & 0.297 & 0.319 & - & & & & \\
\hline $\begin{array}{l}\text { CCC (Campus and } \\
\text { Clinton-Como) }\end{array}$ & 18 & 0.295 & 0.387 & 0.288 & 0.341 & 0.234 & - & & & \\
\hline SCI (Scioto River) & 2 & 0.406 & 0.416 & 0.422 & 0.416 & 0.386 & 0.422 & - & & \\
\hline CIN (Cincinnati) & 5 & 0.251 & 0.298 & 0.363 & 0.353 & 0.405 & 0.413 & 0.455 & - & \\
\hline CLE (Cleveland) & 8 & 0.270 & 0.440 & 0.426 & 0.465 & 0.418 & 0.417 & 0.459 & 0.468 & - \\
\hline
\end{tabular}

\section{Genetic variation is structured across regions}

Analyses of molecular variance with all samples showed that $17 \%$ of genetic variation was partitioned among regions (Table S4). Further partitioning among populations did not explain additional variation (Table S4). The remaining $83 \%$ of variation existed within regions, meaning that individuals' genotypes were highly variable. Similarly, for Columbus, separating by region explained $14 \%$ of variation and negligible variation was partitioned among populations, meaning $86 \%$ of variation existed within regions (Table S4).

For analysis of the full dataset, $\mathrm{K}=2$ was most strongly supported by STRUCTURE Harvester and CLUMPP results, but $\mathrm{K}=3$ was also somewhat supported (Table S5). The four a priori regions (Cincinnati, Cleveland, East Columbus, Central Columbus) corresponded relatively well to the clusters (Fig. 2,3). The $\mathrm{K}=3$ solution had the advantage of grouping Cleveland individuals together as their own unique cluster according to both STRUCTURE (Fig. 2f,h) and PCoA (Fig. 3c). Individuals in the Cleveland cluster also had more homogenous genotypes than those in other regions (Fig. 2h). Columbus individuals separated approximately across the Central (CAT, CCC, SCI) versus the East (BSP, BTC, BWC) regions according to STRUCTURE (Fig. 2b,d) and PCoA (Fig. 3b), with Cincinnati grouped with East Columbus (Fig. 2a,d; 3a,c).

Concordantly, analysis of Columbus samples alone strongly supported $\mathrm{K}=2$, with much less support for $\mathrm{K}=3$ (Table S5). Clusters again mapped relatively well to regions, with the Central Columbus cluster uniting CAT and CCC, while BSP, BTC, and BWC formed the East Columbus cluster (Fig. 2c,e; $3 b$ ). The final Columbus population, $\mathrm{SCl}$, is in Central Columbus but is downstream of the confluence with the East Columbus watershed. Of the two $\mathrm{SCl}$ individuals in our dataset, one was assigned with high probability to the East Columbus cluster and one to Central Columbus (Fig. 2e). Within regions, most individuals' genotypes aligned with the corresponding cluster, but some showed signs of admixture (Fig. 2e).

\section{Bulbil producing subspecies predominate across regions}

Axillary bulbil formation, which distinguishes verna and ficariiformis from the other subspecies, was observed in at least one individual collected from each of the 43 collection sites. Only 12 of 129 individuals failed to produce bulbils, and these were scattered across all five regions. Larger individuals were more likely to produce axillary bulbils, based on our use of the number of tubers as a proxy for biomass ( $p=0.014$, Wilcoxon rank sum test with continuity correction, Miller and Miller 2014). Across regions, observed trait means for leaf blade width (Fig. 4a), petiole length (Fig. 4i), and petal length (Fig. 4e) largely support a designation of verna. Some important floral traits are not aligned with verna, however. The petal lengths of a few individuals 
spread across regions aligned with the diagnostic ficariiformis petal length of $>13.5 \mathrm{~mm}$ described by Post et al. (2009) in North America and Veldkamp (2015) in Europe (Fig. 4e). Lengthened achenes across regions supported ficariiformis (Fig. 4h). Mean petal widths for Cleveland samples were small enough to align with verna, while East and Central Columbus had larger petal widths more characteristic of ficariiformis (Fig. 4d). None of the Cincinnati plants flowered.

Table 3

Results of linear mixed effects models comparing traits across regions (Cincinnati, Cleveland, East Columbus, and Central Columbus) and correlations between traits and genetic distance at the population level. Model p-values were generated with Type III F tests. For Mantel tests, we report two-tailed $p$-values. Bold denotes $p<0.05$, italics $0.05<p<0.10$.

\begin{tabular}{|c|c|c|c|c|c|c|}
\hline \multicolumn{4}{|c|}{ Linear mixed effects p-values } & \multicolumn{3}{|c|}{ Mantel test p-values } \\
\hline Trait name & $\begin{array}{l}\text { Region of } \\
\text { collection }\end{array}$ & $\begin{array}{l}\text { Number of tubers } \\
\text { (covariate) }\end{array}$ & $\begin{array}{l}\text { Collection date } \\
\text { (covariate) }\end{array}$ & $\begin{array}{l}\text { Trait } \\
\text { means }\end{array}$ & $\begin{array}{l}\text { Trait } \\
\text { variance }\end{array}$ & $\begin{array}{l}\text { Figure } 4 \\
\text { panel }\end{array}$ \\
\hline Leaf blade width & 0.870 & $<0.001$ & 0.164 & 0.467 & 0.010 & a \\
\hline $\begin{array}{l}\text { Leaf blade } \\
\text { length:width ratio }\end{array}$ & $<0.001$ & 0.020 & 0.484 & 0.058 & 0.820 & $b$ \\
\hline Leaf lobe length & 0.695 & $<0.001$ & 0.866 & 0.498 & 0.346 & c \\
\hline Petal width & 0.006 & 0.059 & 0.789 & 0.813 & 0.269 & $d$ \\
\hline Petal length & 0.018 & $<0.001$ & 0.927 & 0.422 & 0.538 & $\mathrm{e}$ \\
\hline $\begin{array}{l}\text { Carpel whorl } \\
\text { diameter }\end{array}$ & $<0.001$ & 0.004 & 0.655 & 0.349 & 0.039 & $f$ \\
\hline Sepal length & 0.522 & 0.090 & 0.771 & 0.985 & 0.473 & $g$ \\
\hline $\begin{array}{l}\text { Maximum achene } \\
\text { length }\end{array}$ & 0.558 & 0.198 & 0.593 & 0.905 & 0.657 & $\mathrm{~h}$ \\
\hline Leaf petiole length & 0.018 & $<0.001$ & 0.569 & 0.241 & 0.478 & $\mathrm{i}$ \\
\hline
\end{tabular}

\section{Floral and leaf traits vary across regions, some corresponding to genetic variation}

After accounting for differences due to size (number of tubers covariate, Table 3), multiple leaf and floral traits varied across regions. Leaves from Cleveland plants were longer than those from Cincinnati, East Columbus, or Central Columbus (Table 3, Fig. 4b), and populations that were similar genetically trended towards also being similar morphologically for this trait $(r=0.512, p=0.058$, Table 3). Genetic distance was not correlated with variance in the leaf length:width ratio (Table 3) but was correlated with variance in width $(r=0.407, p=0.010)$, suggesting that genetic similarity corresponds to the magnitude of variability in this trait. Petiole length differed between the two Columbus regions, with plants from East Columbus having longer petioles than those from Central Columbus (Table 3, Fig. 4i). Petals were longer for East Columbus than Central Columbus or Cleveland plants (Table 3, Fig. 4e) and wider for East Columbus than Cleveland plants (Table 3, Fig. 4d). East Columbus had plants with the largest carpel whorls, followed by Central Columbus, with Cleveland having the smallest whorls (Table 3, Fig. 4f). Variance differences in carpel whorl diameter were also correlated with genetic distance, indicating correspondence between genetic variation and trait variation for this trait $(r=0.755, p=0.039$, Table 3$)$.

\section{Isolation by distance, water dispersal, and habitat contribute to genetic structure}

Greater Euclidean distance corresponded to greater genetic distance $\left(\beta_{\mathrm{std}}=0.013, \mathrm{p}=0.004, \mathrm{Table} 4\right)$. Both predictors related to water dispersal, distance to stream $\left(\beta_{\text {std }}=-0.008, p<0.001\right.$, Table 4) and flow distance $\left(\beta_{\text {std }}=-0.008, p<0.001\right.$, Table 4), significantly predicted genetic distance. The negative relationship of genetic distance to each of these variables suggests greater genetic differentiation in individuals that are closer to streams, and in those separated from other individuals by greater downstream distance via streams. Some estimated resistances also predicted genetic distance. For sand $\left(\beta_{\text {std }}=-0.017, p<0.001\right.$, 
Table 4), examination of the shape of the relationship between predictor and resistance values (Fig. S2d) showed that the lowest resistance (i.e., highest potential for gene flow) was around 35\% soil sand content. Both low and high sand contents showed high resistance (i.e., barriers to gene flow) -though observations on the low end of the range were scarce (Fig. S2d). For development categories ( $\beta_{\text {std }}=0.021, p<0.001$, Table 4; Fig. S2b), we saw the lowest resistance (1) for the developed, open space classification (developed areas with 0-20\% impervious surface in a raster cell). Non-developed land also had relatively low resistance (491.871) when compared to much higher resistance (all $>204240$ ) of more intensively developed categories (those with $>20 \%$ impervious surface). This finding indicated highly developed land may limit celandine establishment. Income was marginally significantly related to genetic distance $\left(\beta_{\text {std }}=0.016, p=0.059\right.$, Table 4). High-income census tracts had the lowest resistance (Fig. S2C), suggesting these were more likely to facilitate establishment and/or dispersal of new propagules than low-income tracts.

Table 4

Relationships of genetic distance among celandine samples from Columbus $(n=51)$ to spatial predictors estimated via maximum likelihood population effects mixed modelling (Clarke et al. 2002; ResistanceGA::mlpe_rga, Peterman 2018). Model coefficients $\left(\beta_{\text {std }}\right)$ were estimated from centered and scaled predictors. Coefficients for resistances are interpreted based on the shape of the relationship between raster values and resistance (Fig. S2). Model p-values are from type III Wald X² tests. Bold denotes $\mathrm{p}<0.05$, italics $0.05<\mathrm{p}<0.10$.

\begin{tabular}{|llllll|}
\hline & Predictor & $\boldsymbol{\beta}_{\text {std }}$ & $\mathbf{X}^{2}$ & $\mathbf{p}$ & VIF \\
\hline Final model & Development (resistance) & 0.021 & 27.123 & $<0.001$ & 2.965 \\
\cline { 2 - 6 } & Distance to stream & -0.008 & 11.284 & $<0.001$ & 1.001 \\
\hline & Flow distance & -0.008 & 10.826 & $<0.001$ & 1.129 \\
\hline & Sand (resistance) & -0.017 & 10.311 & $<0.001$ & 2.302 \\
\hline \multirow{2}{*}{ Initial models } & Euclidean distance & 0.013 & 8.444 & $\mathbf{0 . 0 0 4}$ & 3.755 \\
\hline & Income (resistance) & 0.016 & 3.574 & 0.059 & 5.299 \\
& Canopy (resistance) & -0.004 & 0.095 & 0.757 & 16.785 \\
\hline & Slope (resistance) & -0.001 & 0.009 & 0.924 & 4.902 \\
\hline
\end{tabular}

The five significant spatially explicit predictors together explained $9 \%$ of genetic variation in the Columbus data $\left(R^{2}=0.090\right)$, leaving a large portion of variation unexplained. We previously showed that analyses of molecular variance indicated $14 \%$ of variation was partitioned among the two Columbus regions (Table S4), but it is unclear how much overlap exists between the variation explained by these two different analyses.

\section{Discussion}

Characterizing patterns of genetic and morphological diversity across our rapidly changing urban landscapes can help us retrospectively understand species' paths from introduction to invasiveness and can help predict future patterns or mechanisms of spread (Borden and Flory 2021). Other studies have estimated genetic and morphological diversity of European celandine populations, and these serve as a basis for comparing diversity in the introduced range. Our population estimates of Nei's genetic diversity ranged from 0.251 to 0.406 , while those estimated in Europe have varied widely: 0.05-0.22 using RAPD (Reisch and Scheitler 2008) and 0.41-1.00 using AFLP (Popelka et al. 2019), meaning that some introduced populations may be more genetically diverse than native populations (assuming diversity estimates were not biased by sampling artifacts). Previous work synthesizing comparisons of genetic diversity among introduced and native populations similarly showed wide variation in outcomes, with a trend towards higher genetic diversity in cases of multiple introductions 
(Dlugosch and Parker 2008). Increased genetic diversity can be important in overcoming genetic Allee effects in introduced species, facilitating shifts from clonal to sexual reproduction (Kettenring et al. 2011).

Relatively high genetic variation both across regions and within regions further suggests admixture among a variety of propagule sources, particularly within the well-sampled Columbus area. Genetic data indicated a degree of separation between the East and Central Columbus watersheds. Traits also differentiated along these lines, with East Columbus populations having larger flowers and longer leaf petioles. Central Columbus populations were thus intermediate between East Columbus and Cleveland in multiple traits. Interestingly, Central Columbus also had relatively high genetic diversity. The Columbus invasion is presumably newer than Cleveland or Cincinnati (Lawrence 1971; OSU MBD 2021), so the finding of higher genetic diversity there is consistent with the idea that a newer invasion would have had less time for populations influenced by multiple introductions to become homogenized in their genetics and traits. While this observation could be a sample size artifact, patterns based on the samples we do have could be interpreted as evidence that Columbus, but not Cleveland or Cincinnati, has experienced multiple introductions, perhaps with different source materials in each Columbus watershed.

The diversity we documented showed that celandine in our study likely did not capture the full genetic variation and morphological breadth known for the species, and indeed may have captured only a fraction of diversity within the two bulbiferous subspecies. The genetic clusters and trait differences did not map neatly onto the subspecies identifications, which is relevant because subspecies have been used in the past to demarcate differences in reproductive mode (Sell 1994; Veldkamp 2015). We did find that bulbil-producing subspecies were widespread across regions. Most trait data supported subspecies verna, and ficariiformis (or genotypes with traits from either) also appear to be present. We encountered difficulties attempting to assign plants to subspecies based on published keys. Other authors have also noted difficulties in distinguishing the subspecies (Post et al. 2009; Whittemore 2020). The Sell (1994) and Veldkamp (2015) keys list achene length as a major break distinguishing the two bulbiferous subspecies. Our measured achene lengths ( $5 \mathrm{~mm})$ correspond to ficariiformis, but the other identifying traits correspond to verna (synonymized in Sell [1994] and Post et al. [2009] as subsp. bulbilifer). Similarly, the Post et al. (2009) key uses a flower petal length cut-off to distinguish the two subspecies, and our observations fall around that cut-off. Across regions, the largest leaved and largest flowered plants (most ficariiformistike) were from East Columbus, and Cleveland plants were the smallest (more verna-like). This observation is also consistent with the genetic results separating Cleveland from East Columbus more than from Central Columbus. Seed enlargement is likelier in ficariiformis than verna (Sell 1994; Veldkamp 2015), so regions like East Columbus having apparently more ficariiformis influence might have more potential to spread via seed.

In all, we found combinations of traits that do not align well with single subspecies. Our identifications also somewhat contrast a previous survey of North American subspecies distributions, which found mostly verna and calthifolius, while ficariiformis was rare (Post et al. 2009). There could be multiple explanations for these discrepancies. First, the taxonomic keys we used (Sell 1994; Veldkamp 2015) were developed in Europe and might not apply exactly to trait values measured in North America. The other source of information we used was based on herbarium specimens from North America (Post et al. 2009), which had small sample sizes (Fig. 4) for some traits and subspecies. Both of these studies used specimens collected from natural populations, while our experiment measured traits of living plants grown under controlled conditions. Others have observed that celandine morphology varies widely and intergrades among subspecies (Whittemore 2020) and that growing celandine in a common garden can homogenize some apparently identifying traits that vary in wild-grown plants (Jones 1966, as cited by Taylor and Markham 1978). Particularly at risk of being mismeasured in wild specimens is bulbil production; we observed that production of axillary bulbils occurred only just before senescence in May. Herbarium specimens used by Post et al. (2009) could have been incorrectly scored for bulbil absence, particularly those collected earlier in the season. Bulbil production is not only an important key break in keys separating verna and ficariiformis from the other subspecies, but it is also of high ecological relevance as a clonal propagule. These observations, combined with our own finding that floral and leaf trait values depend strongly on biomass (Table 3), suggest the putative subspecies might be more similar than suspected by some taxonomists. 
Future attempts to delineate these cryptic subspecies might benefit from relying on traits found to be correlated with genetic markers. In our study, the first to correlate traits and genetics, leaf blade length:width ratio was the mean trait most strongly associated with population-level genetic distances. We utilized SRAPs to discern genetic variation in celandine, while other studies have used AFLP (Popelka et al. 2019) and RAPD (Reisch and Scheitler 2008). The number of SRAP loci we used, four, was on the low end compared to a survey of other SRAP studies (Robarts and Wolfe 2014). However, these markers yielded a higher number of fragments per locus (41.5 vs. 11.8, Robarts and Wolfe 2014) and rate of polymorphism (99.4\% vs. 68.7\%). Our markers were also highly reproducible, due to the conservative repeatability thresholds we used. Future researchers interested in understanding genetic differences between subspecies and populations have a toolbox of accessible markers to study this increasingly important invader.

Regardless of subspecies identities, our regional comparisons of traits, particularly reproductive modes, also provide insight into the biology and spread of this species. We found almost every individual reproduced clonally by making bulbils. We also saw a strong dependence of axillary bulbil production on biomass (through the proxy of number of tubers). Since celandine is a perennial and uses its belowground tubers for energy storage, it makes sense that larger plants with more resources would have the ability to invest in clonal dispersal. The most surprising result related to reproductive mode was that many plants across regions produced expanded achenes. Reportedly, seed enlargement in verna is rare (Sell 1994) or absent (Post et al. 2009; Veldkamp 2015). Anecdotally, Columbus populations had been observed to set seed (pers. obs.). In Louisville, previous work has recorded fertile seeds (Masters and Emery 2015). However, wild Cleveland populations seem not to produce expanded achenes (pers. obs.). In our experiment, achene production in the Cleveland individuals might be explained by the simultaneous blooming of flowers from Cleveland with those from Columbus or Louisville, coupled with the presence of insect pollinators at the common garden site, which could have led to cross pollination among individuals from different populations or regions. Because verna (the identification most appropriate for Cleveland) can exhibit low pollen viability (Sell 1994), introduction of even a few individuals of another subspecies (potentially ficariiformis based on our data) could serve an outsized role in facilitating sexual reproduction. In Cleveland, low diversity relative to other regions might prevent individuals from crossing, whereas crossing may be possible with more differentiated genotypes. In fact, small flower size distinguished the low-diversity Cleveland individuals, and amount of variance in this trait was related to genetic differentiation among populations. Smaller flowers could reduce propensity to cross via pollen limitation or less apparent pollinator displays. Cincinnati also had relatively low genetic diversity, but this may reflect the fewer genetic samples we had from this region. Cincinnati plants did not flower, possibly due to their smaller size (several had as few as one tuber, a potential sampling bias) or due to differences in original site quality, as flowering has been shown to be influenced by the preceding year's weather (Tyler 2001). Regardless, we cannot speak to the potential of the Cincinnati individuals to produce seeds. The reproductive diversity we documented both across and within regions, taken together with patterns of genetic diversity, may suggest a history of multiple introductions from the native range and subsequent admixture.

Land managers should be wary of new introductions that might bring in new genetic diversity, facilitate seed production, and potentially worsen invasion severity. However, there are multiple caveats to our achene production findings. We did not test the viability of the expanded achenes, though viability is at least known within Louisville (Masters and Emery 2015). We also did not control pollination in the experiment and so cannot distinguish between achenes that were fertilized by pollen from the same region, another region, or from the same plant (selfing). Furthermore, we do not know if apomixis occurred or whether the expanded achenes had no embryo inside, both of which have been previously documented in bulbiferous celandine (Metcalfe 1939). Still, more recent work has shown that bulbiferous tetraploids (specifically verna) can produce fertile seeds (Popelka et al. 2019), through either cross pollination or self-pollination (Marsden-Jones and Turrill 1952). Despite these caveats, the potential that ripened achenes were produced raises the possibility that sexual reproduction is possible for introduced celandine populations.

Our genetic data provide further evidence for sexual reproduction. First, we investigated whether any clones were present among the individuals we genotyped. Clones might be expected to be common, especially for this apparently verna-dominated region. However, genetic analyses indicated that we collected no clones. We also observed high genetic admixture at the individual level, suggesting sexual reproduction may be recombining genotypes. Taking a broader view, sexual reproduction

Page 14/23 
and seed production indicate a greater potential for evolutionary change than clonal reproduction alone. In novel urban conditions and stress regimes, sexual reproduction could be particularly important in facilitating adaptation of introduced species.

We found some support for hypotheses regarding vectors and habitat factors thought to contribute to genetic differentiation, whether through enhanced dispersal or establishment of new propagules. These factors together explained only a small portion of genetic variation, further consistent with a new invader having modest genetic structure. We found evidence of isolation by distance and genetic differentiation via water dispersal and across habitats. Greater opportunities for water dispersal were associated with greater genetic differentiation. The opposite trend might be expected for asexual dispersal, wherein greater connectivity leads to more gene flow across the landscape, resulting in homogenous populations of clones. However, the pattern we observed here is consistent with the aforementioned pattern of increased achene production (potentially via sexual reproduction) when individuals that differ more genetically are more connected, or when the immigration of more differentiated genotypes is possible. This further points to the idea of a genetic diversity Allee effect in introduced populations of this species, wherein overcoming a threshold of genetic diversity may have been a mechanism by which celandine has increased its spread in recent years.

Our finding that sand content in the soil was associated with genetic distance is consistent with previous work showing that sandy soil is associated with lower asexual production and is not optimal for this species (Kermack and Rauschert 2019). We found the lowest resistance around $35 \%$ sand content, suggesting optimal conditions for celandine might be found in less sandy soils including clays, clay loams, loams, silty loams, silty clays, silty clay loams, and silts. At the landscape scale, areas with these soil types might be prioritized for monitoring and management over those having sandier soils.

Our analyses also implicated the role of human development in structuring celandine populations. Highly developed land inhospitable to wild plant growth had commensurately high resistance. This pattern also qualitatively corresponds to the East/Central divide in Columbus-these two genetically distinct regions are separated by high intensity development. Developed areas with open space and low impervious surface (such as lawns) were most conducive to celandine establishment and dispersal, consistent with celandine's history as an escaped horticultural species. Non-developed areas also had relatively high potential for and could be vanguards of future spread from cities into more rural areas. High-income census tracts, which are perhaps likeliest to do active landscaping, were most likely to facilitate celandine establishment or dispersal. Resistances for development and income were significantly positively correlated $(r=0.727, p<0.001)$, meaning that high-income properties (corresponding to high gene flow) corresponded with the open space development category (also corresponding to high gene flow). Therefore, in this landscape these two factors may interact to facilitate celandine. In other areas where highincome properties are also less developed, such as urban areas with wealthy suburbs, these two socioeconomic factors might also act in synergy to facilitate gene flow.

Our work has shown that both clonal spread and seed production appear to be important in the spread of this species that commonly invades waterways in urban areas. We documented widespread axillary bulbil production, and achene production was not uncommon. We also saw a potential relationship between the ability to produce achenes and genetic diversity. In the well-sampled Columbus area, we found evidence for multiple introductions and subsequent admixture. Finally, we found support for various factors thought to be important in structuring celandine establishment and dispersal, including soil sand content, human development, and a potential role of water dispersal in connecting diverse populations. These findings together elucidate the reproductive biology and patterns of spread in this increasingly common invader of urban forest fragments and suggest celandine may have substantial evolutionary potential in response to novel anthropogenic selective agents.

\section{Declarations}

\section{Acknowledgements}

We are grateful for the help of Jennifer Hillmer and Pat Lorch of the Cleveland Metroparks and Paul Pira of the Geauga Park District for assistance with sites. We thank Dr. Michael Broe, Leah Weston, Scott Martin, and Dr. Bill Peterman for assistance 
with analyses and Dr. Alison Bennett, Alexis Wafer, and Dr. Andi Wolfe for feedback on analyses and writing. We thank the Cornell University Biotechnology Resource Center for fragment analysis services. For lab assistance, we thank Eleanor Chase. For facilities support, we thank Ohio State's Biological Sciences and Biotechnology Support Greenhouses, Center for Applied Plant Sciences, Gary Posey, David Snodgrass, and Emily Yoders-Horn. This work was supported by the Ohio State Alumni Grant for Graduate Research and Scholarship and Presidential Fellowship to KZM and start-up funds to SMH.

Funding: This work was supported by the Ohio State Alumni Grant for Graduate Research and Scholarship and Presidential Fellowship to KZM and start-up funds to SMH.

Competing interests: The authors declare that they have no competing interests.

Data availability: Data will be uploaded to Dryad upon manuscript acceptance.

Code availability: Code will be uploaded to Dryad upon manuscript acceptance.

Author contributions: SMH, CTCD, and AT together designed the project. CTCD, ESJR, and AT oversaw surveys and data collection, supervised by SMH. CTCD and KZM developed genetics protocols, KZM and AT executed genetic analyses, and AT performed morphological sampling. KZM and AT analysed and interpreted data, supervised by SMH and ESJR. KZM wrote the manuscript with contributions from AT, SMH, and ESJR. All authors reviewed and approved the final manuscript.

\section{References}

1. Arnaud-Haond SO, Belkhir KH (2007) GENCLONE: a computer program to analyse genotypic data, test for clonality and describe spatial clonal organization. Mol Ecol Notes 7:15-7.

2. Arnaud-Haond SO, Duarte CM, Alberto F, Serrão EA (2007) Standardizing methods to address clonality in population studies. Mol Ecol 16:5115-5139.

3. Arredondo TM, Marchini GL, Cruzan MB (2018) Evidence for human-mediated range expansion and gene flow in an invasive grass. P R Soc B 285:20181125.

4. Arrigo N, Tuszynski JW, Ehrich D, Gerdes T, Alvarez N (2009) Evaluating the impact of scoring parameters on the structure of intra-specific genetic variation using RawGeno, an R package for automating AFLP scoring. BMC Bioinformatics 10:33.

5. Arrigo N, Holderegger R, Alvarez N (2012) Automated scoring of AFLPs using RawGeno v 2.0, a free R CRAN library. In: Pompanon F, Bonin A (eds) Data production and analysis in population genomics. Humana Press, Totowa, NJ, pp 155175.

6. Axtell AE, DiTommaso A, Post AR (2010) Lesser celandine (Ranunculus ficaria): a threat to woodland habitats in the Northern United States and Southern Canada. Invas Plant Sci Mana 3:190-96.

7. Bailleul D, Stoeckel S, Arnaud-Haond S (2016) RClone: a package to identify MultiLocus Clonal Lineages and handle clonal data sets in R. Methods Ecol Evol 7:966-70.

8. Baker HG (1955) Self-compatibility and establishment after "long-distance" dispersal. Evolution 9:347-349.

9. Barrett SCH (2015) Influences of clonality on plant sexual reproduction. P Natl Acad Sci USA 112:8859-66.

10. Barton K (2020) MuMIn: multi-model inference. R package version 1.43.17. https://CRAN.R-project.org/package=MuMIn

11. Bates D, Mächler M, Bolker B, Walker S (2015) Fitting linear mixed-effects models using Ime4. J Stat Softw 67:1-48.

12. Borden JB, Flory SL (2021) Urban evolution of invasive species. Front Ecol Environ 19:184-191.

13. Clarke RT, Rothery P, Raybould AF (2002) Confidence limits for regression relationships between distance matrices: estimating gene flow with distance. J Agr Biol and Envir St 7:361-372.

14. Dewitz J (2019) National land cover database 2016 products (ver. 2.0, July 2020): United States Geological Survey data release. https://doi.org/10.5066/P96HHBIE. Accessed 5 November 2020.

15. DeWoody JA, Schupp J, Kenefic L, Busch J, Murfitt L, Keim P (2004) Universal method for producing ROX-labeled size standards suitable for automated genotyping. Biotechniques 37:348-352. 
16. Dice L (1945) Measures of the amount of ecologic association between species. Ecology 26:297-302.

17. Dlugosch KM, Parker IM (2008) Founding events in species invasions: genetic variation, adaptive evolution, and the role of multiple introductions. Mol Ecol 17:431- 449.

18. Doyle JJ, Doyle JL (1987) A rapid DNA isolation procedure for small quantities of fresh leaf tissue. Phytochem Bull 19:1115.

19. Dray S, Dufour A (2007) The ade4 package: implementing the duality diagram for ecologists. J Stat Softw 22:1-20.

20. Earl DA, vonHoldt BM (2012) STRUCTURE HARVESTER: a website and program for visualizing STRUCTURE output and implementing the Evanno method. Conserv Genet Resour 4:359-361.

21. Emadzade K, Lehnebach C, Lockhart P, Hörandl E (2010) A molecular phylogeny, morphology and classification of genera of Ranunculeae (Ranunculaceae). Taxon 59: 809-28.

22. ESRI (2018) Environmental Systems Research Institute ArcGIS Pro release 2.2.0. Redlands, CA.

23. Evanno G, Regnaut S, Goudet J (2005) Detecting the number of clusters of individuals using the software STRUCTURE: a simulation study. Mol Ecol 14:2611-2620.

24. Falush D, Stephens M, Pritchard JK (2007) Inference of population structure using multilocus genotype data: dominant markers and null alleles. Mol Ecol Notes 7:574-578.

25. Fox J, Weisberg S (2019) An R companion to applied regression. 3rd edn, Sage, Thousand Oaks, CA.

26. Gill JJ, Jones BM, Marchant CJ, McLeish J, Ockendon DJ (1972) The distribution of chromosome races of Ranunculus ficaria L. in the British Isles. Ann Bot 36:31-47.

27. Herrmann M, Holderegger R, Van Strien MJ (2013) Influence of parameter settings in automated scoring of AFLPs on population genetic analysis. Mol Ecol Resour 13:128-134.

28. Hijmans RJ (2019) geosphere: spherical trigonometry. R package version 1.5-10. https://CRAN.Rproject.org/package $=$ geosphere

29. Jakobsson M, Rosenberg NA (2007) CLUMPP: a cluster matching and permutation program for dealing with label switching and multimodality in analysis of population structure. Bioinformatics 23:1801-1806.

30. Jombart T, Pontier D, Dufour AB (2009) Genetic markers in the playground of multivariate analysis. Heredity 102:330-341.

31. Jones BMG (1966) Variation in Ranunculus ficaria. Proc Bot Soc Br Isl 6:275.

32. Jung F, Böhning-Gaese K, Prinzing A (2008) Life history variation across a riverine landscape: Intermediate levels of disturbance favor sexual reproduction in the ant-dispersed herb Ranunculus ficaria. Ecography 31:776-786.

33. Kamvar ZN, Tabima JF, Grünwald NJ (2014) poppr: an R package for genetic analysis of populations with clonal, partially clonal, and/or sexual reproduction. PeerJ 2:e281.

34. Kermack JP, Rauschert ES (2019) Soil characteristics drive Ficaria verna abundance and reproductive output. Invas Plant Sci Mana 12:214-222.

35. Kettenring KM, McCormick MK, Baron HM, Whigham DF (2011) Mechanisms of Phragmites australis invasion: feedbacks among genetic diversity, nutrients, and sexual reproduction. J Appl Ecol 48:1305-1313.

36. Lavergne S, Molofsky J (2007) Increased genetic variation and evolutionary potential drive the success of an invasive grass. P Natl Acad Sci USA 104:3883-88.

37. Lawrence E (1971) Lob's Wood. Cincinnati Nature Center, Milford, OH.

38. Length RV (2016) Least-squares means: the R package Ismeans. J Stat Softw 69:1-33.

39. Li G, Quiros CF (2001) Sequence-related amplified polymorphism (SRAP), a new marker system based on a simple PCR reaction: its application to mapping and gene tagging in Brassica. Theor Appl Genet 103:455-461.

40. Mack JJ (2008) Workplan for lesser celandine (Ranunculus ficaria) control in Rocky River and Mill Stream Run Reservations, v. 1.0. Cleveland Metroparks Technical Report 2008/NR-05. Division of Natural Resources, Cleveland Metroparks, Fairview Park, Ohio. 
41. Marchant CJ, Brighton CA (1973) Cytological diversity and triploid frequency in a complex population of Ranunculus ficaria L. Ann Bot 38:7-15.

42. Marsden-Jones EM, Turrill WB (1952) Studies on Ranunculus ficaria. J Genet 50: 522-534.

43. Masters JA, Emery SM (2015) The showy invasive plant Ranunculus ficaria facilitates pollinator activity, pollen deposition, but not always seed production for two native spring ephemeral plants. Biol Invasions 17:2329-2337.

44. McKinney ML (2006) Urbanization as a major cause of biotic homogenization. Biol Conserv 127:247-60.

45. McRae BH (2006) Isolation by resistance. Evolution 60:1551-1561.

46. McRae BH, Dickson BG, Keitt TH, Shah VB (2008) Using circuit theory to model connectivity in ecology, evolution, and conservation. Ecology 89:2712-24.

47. Metcalfe CR (1939) The sexual reproduction of Ranunculus ficaria. Ann Bot 3:91-103.

48. Miller I, Miller M (2014) John E. Freund's mathematical statistics with applications. 8th edn, Pearson, Harlow, Essex.

49. Nei M (1978) Estimation of average heterozygosity and genetic distance from a small number of individuals. Genetics 89:583-590.

50. O'Geen A, Walkinshaw M, Beaudette D (2017) SoilWeb: a multifaceted interface to soil survey information. Soil Sci Soc Am J 81:853-862. https://doi.org/10.2136/sssaj2016.11.0386n. Accessed 15 March 2021.

51. OGRIP (2021) Ohio Geographically Referenced Information Program digital elevation models (DEMs). https://ogrip.oit.ohio.gov/ServicesData/GEOhioSpatialInformationPortal/USGSGeodataDistribution(Historical)/DEM.aspx. Accessed 4 March 2021.

52. Ortego J, Bonal R, Muñoz A (2010) Genetic consequences of habitat fragmentation in long-lived tree species: the case of the Mediterranean holm oak (Quercus ilex, L.). J Hered 101:717-26.

53. OSU MBD (2021) Ohio State University Museum of Biological Diversity Herbarium online specimen access. https://herbarium.osu.edu/online-data-access. Accessed 11 August 2021.

54. Peterman WE (2018) ResistanceGA: an R package for the optimization of resistance surfaces using genetic algorithms. Methods Ecol Evol 9:1638-1647.

55. Paolucci A, Rauschert ESJ, Carrino-Kyker S, Burke D (2021) Root fungal communities associated with better performance of an invasive spring ephemeral. Biol Invasions 23:181-192.

56. Popelka O, Sochor M, Duchoslav M (2019) Reciprocal hybridization between diploid Ficaria calthifolia and tetraploid Ficaria verna subsp. verna: evidence from experimental crossing, genome size and molecular markers. Bot J Linn Soc 189:293-310.

57. Post AR, Krings A. Wall WA, Neal JC (2009) Introduced lesser celandine (Ranunculus ficaria, Ranunculaceae) and its putative subspecies in the United States: a morphometric analysis. J Bot Res Inst Tex 3:193-209.

58. Pritchard JK, Stephens M, Donnelly P (2000) Inference of population structure using multilocus genotype data. Genetics 155:945-959.

59. Pyšek P, Richardson DM (2008) Traits associated with invasiveness in alien plants: where do we stand? In: Nentwig W (ed) Ecological studies (analysis and synthesis), vol. 193, Biological invasions, Springer-Verlag, Berlin, Heidelberg, Germany, pp 97-125.

60. R Core Team (2019-20) R: a language and environment for statistical computing. R Foundation for Statistical Computing. Vienna, Austria. http://www.R-project.org/

61. Reisch C, Scheitler S (2008) Disturbance by mowing affects clonal diversity: the genetic structure of Ranunculus ficaria (Ranunculaceae) in meadows and forests. In: van der Valk A (ed) Herbaceous plant ecology, Springer, Dordrecht, Netherlands, pp 335-343.

62. Robarts DWH, Wolfe AD (2014) Sequence-related amplified polymorphism (SRAP) markers: a potential resource for studies in plant molecular biology. Appl Plant Sci 2:1-14. 
63. Schenk MF, Thienpont CN, Koopman WJ, Gilissen LJ, Smulders MJ (2008) Phylogenetic relationships in Betula (Betulaceae) based on AFLP markers. Tree Genet Genomes 4:911-924.

64. Sell PD (1994) Ranunculus ficaria L. sensu lato. Watsonia 20:41-50.

65. Serrote CM, Reiniger LR, Silva KB, dos Santos Rabaiolli SM, Stefanel CM (2020) Determining the polymorphism information content of a molecular marker. Gene 726:144175.

66. Štajerová K, Šmilauer P, Brůna J, Pyšek P (2017) Distribution of invasive plants in urban environment is strongly spatially structured. Landscape Ecol 32:681-92.

67. Taylor K, Markham B (1978) Ranunculus ficaria L. (Ficaria verna Huds.; F. Ranunculoides Moench). J Ecol 66:1011-1031.

68. Tyers M (2020) riverdist: river network distance computation and applications. R package version 0.15.3. https://CRAN.Rproject.org/package=riverdist

69. Tyler G (2001) Relationships between climate and flowering of eight herbs in a Swedish deciduous forest. Ann Bot 87:623630.

70. USCB (2019a) United States Census Bureau American community survey 5-year estimates subject tables: median income in the past 12 months (in 2019 inflation-adjusted dollars). https://data.census.gov/cedsci/table?

$\mathrm{t}=$ Income\%20and\%20Poverty\&g=0500000US39049.140000\&y=2019\&tid=ACSST5Y2019.S1903. Accessed 10 March 2021.

71. USCB (2019b) United States Census Bureau TIGER/line shapefiles: census tracts. https://www.census.gov/cgibin/geo/shapefiles/index.php?year=2019\&layergroup=Census+Tracts. Accessed 10 March 2021.

72. USDA FS (2019) United States Department of Agriculture Forest Service national land cover database 2016 tree canopy cover (CONUS). Salt Lake City, UT. https://www.mrlc.gov/data/nlcd-2016-usfs-tree-canopy-cover-conus. Accessed 23 October 2020.

73. USDA NRCS (2021) USDA Natural Resources Conservation Service. Ranunculus ficaria L. The PLANTS database. National Plant Data Team. Greensboro, NC. https://plants.usda.gov/home/plantProfile?symbol=RAFI. Accessed 28 July 2021.

74. USGS (2014) United States Geological Survey area- and depth-weighted averages of selected SSURGO variables for the conterminous United States and District of Columbia.

https://water.usgs.gov/GIS/metadata/usgswrd/XML/ds866_ssurgo_variables.xml\#stdorder. Accessed 8 March 2021.

75. USGS (2021) United States Geological Survey national hydrography dataset best resolution (NHD) for Hydrologic Unit (HU) 8. https://www.usgs.gov/core-science-systems/ngp/national-hydrography/access-national-hydrography-products. Accessed 14 January 2021.

76. Veldkamp J (2015) De nomenclatuur van Speenkruiden (Ficaria verna Huds. s.I. Ranunculaceae). Gorteria 37: 84-116.

77. Verheyen K, Hermy M (2001) The relative importance of dispersal limitation of vascular plants in secondary forest succession in Muizen Forest, Belgium. J Ecol 89:829-840.

78. Whittemore AT (2020) Ranunculus ficaria. In: Flora of North America Editorial Committee 1993+ (eds) Flora of North America north of Mexico, vol. 3, New York and Oxford. http://floranorthamerica.org/Ranunculus_ficaria. Accessed 19 June 2021.

79. Wolfe AD (2005) ISSR techniques for evolutionary biology. Method Enzymol 395:134-144.

\section{Figures}




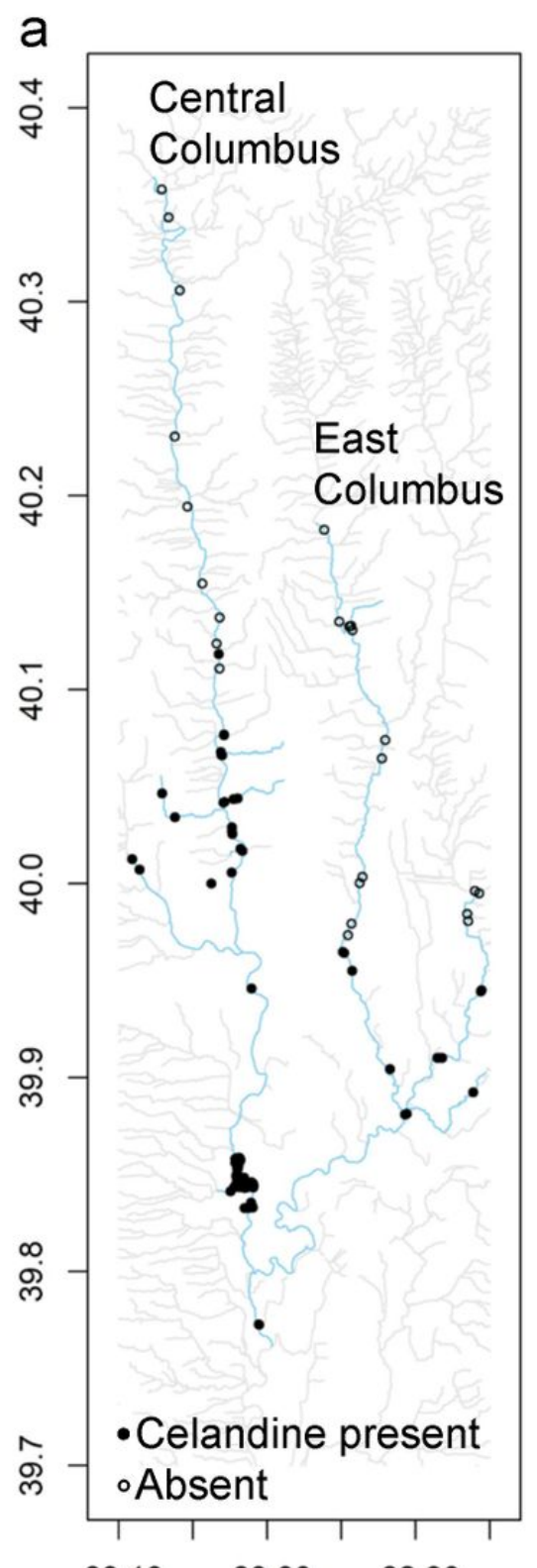

$\begin{array}{lll}-83.10 & -83.00 \quad-82.90\end{array}$ b

ֻัด

Central

Columbus

$\check{q}$

СAT:

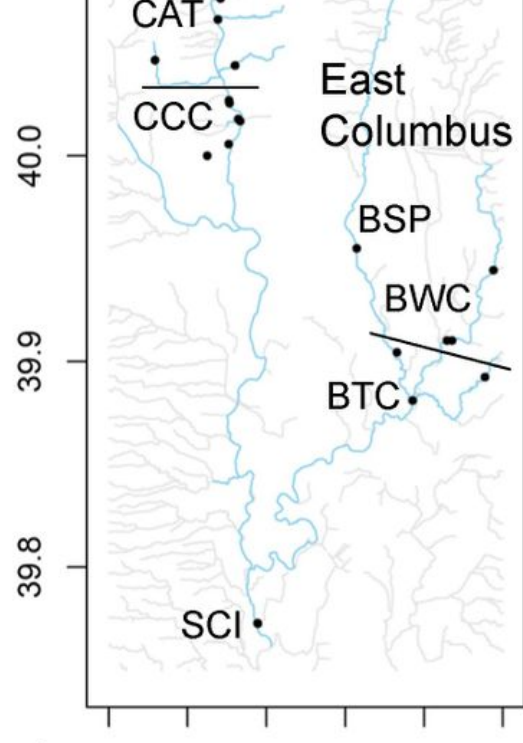

d $-83.10 \quad-83.00 \quad-82.90$

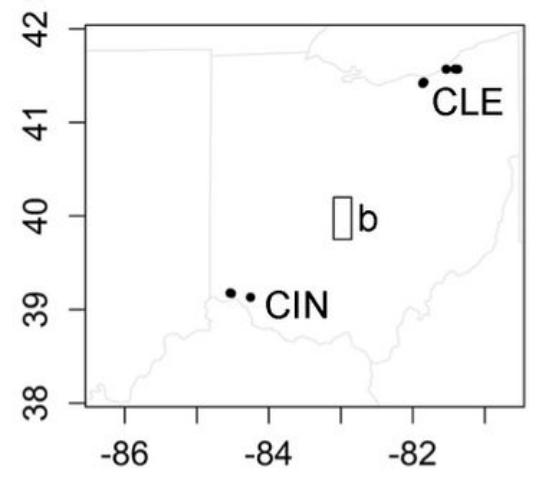

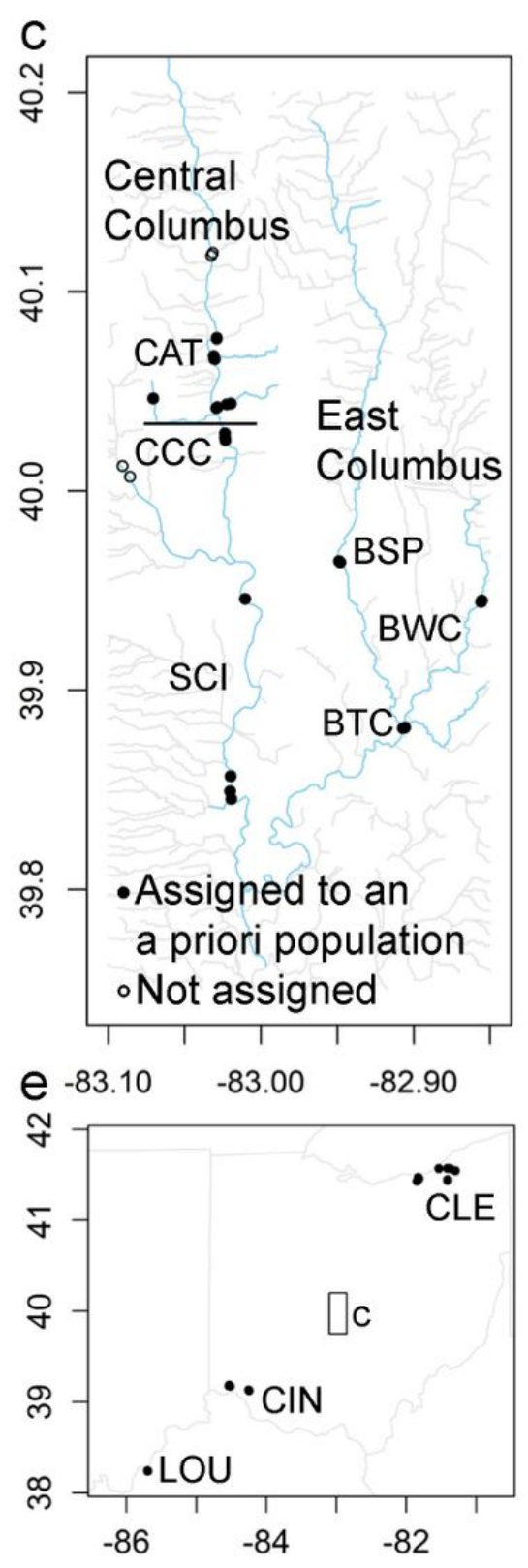

Figure 1

Summary of sampling locations and a priori assignments of regions-Central Columbus, East Columbus, Cleveland (CLE), Cincinnati (CIN), and Louisville (LOU)-and, within regions, populations: BSP (Schneider Park), BTC (Blacklick and Three Creeks), BWC (Big Walnut Creek), CAT (Clintonville and Arlington tributaries), CCC (Campus and Clinton-Como), SCI (Scioto River), CLE, CIN, and LOU. Region and population are synonymous for CLE, CIN, and LOU. For Columbus, sites of a) celandine presence/absence surveys, b) genetic sample collection, c) morphological sample collection. Columbus waterways (USGS 2021) occupied by a celandine GPS point emboldened to highlight the watersheds distinguishing Central Columbus (Scioto and Olentangy Rivers) from East Columbus (Big Walnut, Blacklick, and Alum Creeks). Across all regions, sites of d) genetic sample collection, e) morphological sample collection. 

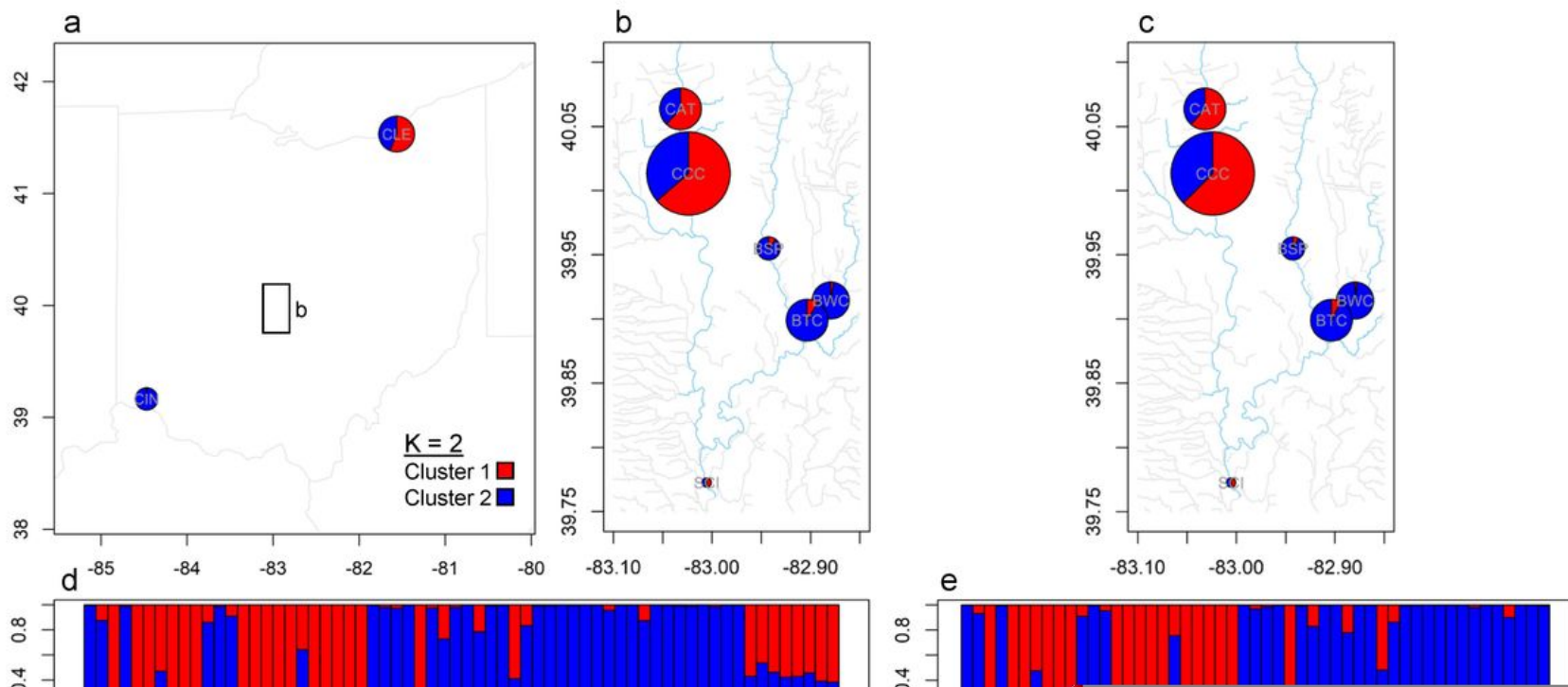

\section{Figure 2}

Maps of STRUCTURE cluster distribution across a priori population assignments (size of points correspond to number of samples in a population) and admixture plots showing assignment probabilities for each individual. Results are shown for: analysis of all data $(n=64)$ with $K=2(a, b, d)$, where $b)$ represents a zoomed inset of a); analysis of Columbus samples $(n=51)$ with $\mathrm{K}=2(\mathrm{c}, \mathrm{e})$; and analysis of all data with $\mathrm{K}=3(\mathrm{f}, \mathrm{g}, \mathrm{h})$, where $\mathrm{g})$ represents a zoomed inset of $\mathrm{f})$.

\section{Figure 3}

Principal coordinates analysis (PCoA) results. Axis labels list variation explained (\%) by a PCo. Point labels are a priori population names. Colors correspond to STRUCTURE clusters, with color gradations corresponding to individual assignment probabilities. a) All data $(n=64)$ with $K=2 ; b)$ Columbus samples $(n=51)$ with $K=2 ; c)$ all data $(n=64)$ with $K=3$. 

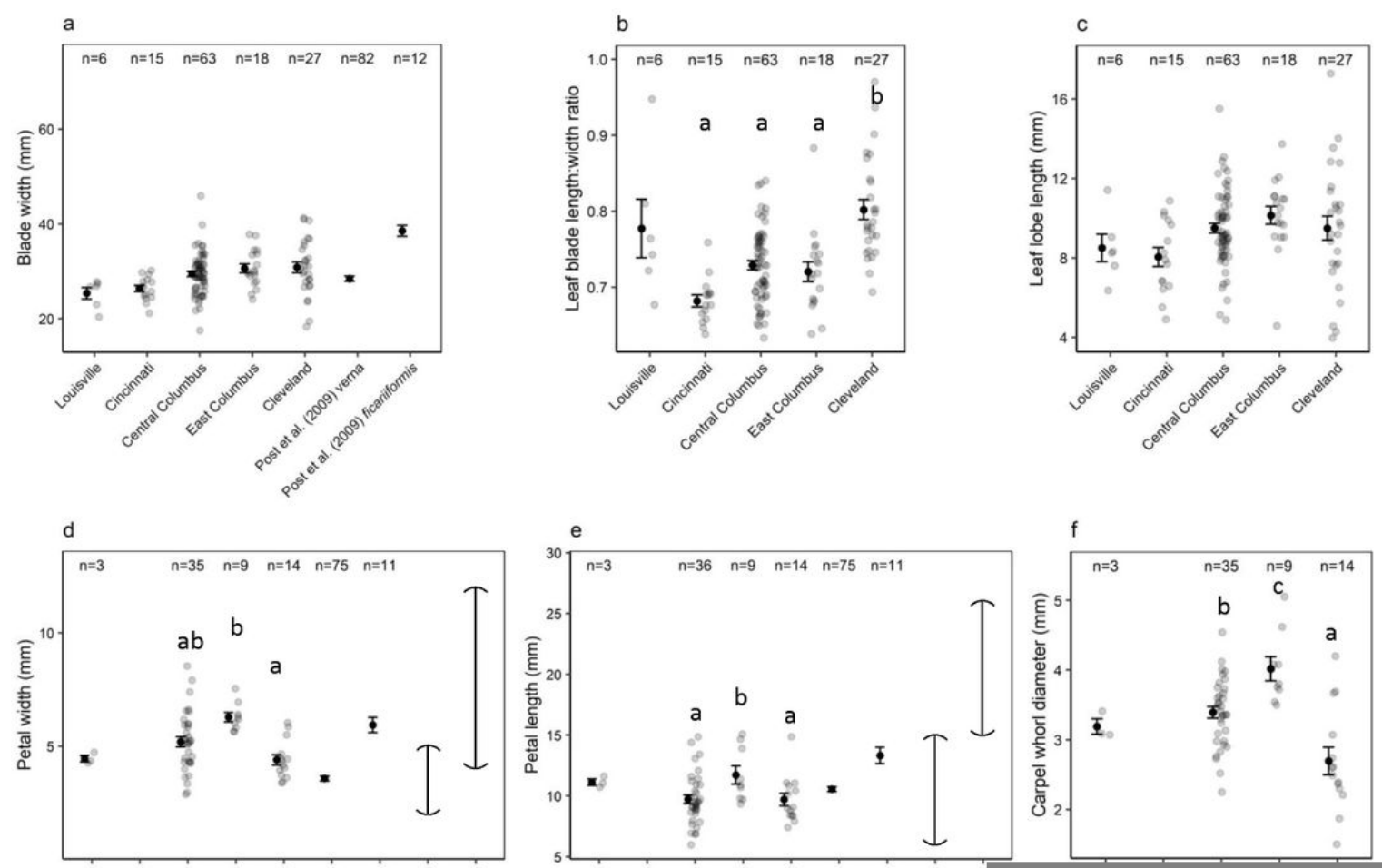

\section{Figure 4}

Trait values by region and, where applicable, from literature descriptions of subspecies verna (syn. bulbilifer) and ficariiformis for a) leaf blade width, b) leaf blade length:width ratio, c) leaf lobe length, d) petal width, e) petal length, f) carpel whorl diameter, g) sepal length, $h$ ) maximum achene length, and i) petiole length. Points are jittered along the $x$-axis to reduce overlap. Square error bars are mean \pm standard error (with group sample sizes, $n$, indicated). Curved error bars are maximum or minimum range values from Veldkamp (2015). For traits that varied significantly by region (Table 3), letters above error bars represent pairwise Tukey-corrected significant differences. Louisville samples were not included in any analyses due to low sample size.

\section{Supplementary Files}

This is a list of supplementary files associated with this preprint. Click to download.

- FigS1.jpg 
- FigS2.jpg

- Tables1.docx

- Tables2.docx

- TableS3.docx

- TableS4.docx

- Tables5.docx 